\title{
Contemporary Chinese Architects and Type: Courtyard based Case Studies in Shanghai Area
}

\author{
By Ioanni Delsante* \\ Cong Zheng ${ }^{\prime}$
}

The concept of architectural type, even if stated since the 19th century, gained much attention in the theoretical debate since the 1960s, especially in Europe. The impact on architectural theory and design has been relevant as well, especially with reference to architects such as Aldo Rossi and Rafael Moneo, among many others. Given the debate unfolded over more than four decades, including various forms of criticism, the concept is nowadays used by very few architects in their practice. However, there is room for further investigation and for deeper understanding of current uses and interpretations of type in contemporary architectural theory and practice. The authors provide a framework of vernacular architecture and types in China and, by analyzing some courtyard-based case studies recently built in the area of Shanghai, identify architectural type as one of the potential design pathways for contemporary Chinese architects. By referring to type, for example, contemporary Chinese architects mediate modernity with tradition, and oppose cultural resistance to trivialization in urbanization processes. The paper builds on an extensive literature review on type in architecture, as well as on vernacular and contemporary Chinese architectures. Qualitative research methods have been used through case studies and interviews with designers.

\section{Introduction}

Quatremère de Quincy was the first to formally introduce the concept of 'type' to architecture in the third volume of his Encyclopédie méthodique: Architecture in 1825, stating also the difference with the model: "the model understood as part of the practical execution of art is an object which should be imitated for what it is. The 'type' on the other hand is something in relation to which different people may conceive works of art having no obvious resemblance to each other. All is exact and defined in the model; in the 'type' everything is more or less vague. The imitation of 'types' therefore has nothing about it which defies the operation of sentiment and intelligence [...]".

According to Argan ${ }^{1}$ even if there might be infinite classes and subclasses, 'types' lay in three main categories concerned with complete configuration of buildings, major structural elements and decorative elements.

He also stated how 'type' is "formed through a process of reducing a complex of formal variants to a common root form", so the vagueness of 'type' is not a definite form but more of a schema. Types are deprived of the specific character

\footnotetext{
${ }^{*}$ Reader, University of Huddersfield, UK.

${ }^{\dagger} \mathrm{PhD}$ Candidate, Tongji University, China.

1. Giulio C. Argan, "Sul concetto di tipologia architettonica," in Festsschrift für Hans Sedlmayr (ed.) Karl Oettinger and Mohammed Rassem. Munich: Beck, 1962, 98.
} 
and "true quality as forms" and sublimated into the indefinite value of an image or a sign.

However, typology is "not just a classifying or statistical process but one carried out for definite formal ends". In fact typological series "do not arise only in relation to the physical functions of buildings but are tied to their configuration".

Following these considerations, we can assume that there are two definite moments in the use of type, one referred to typology and the other to the definition of form. To better understand this point, the matter of type should be evaluated in relationship to the artist's creative process.

The first is not problematic, as it implies the acceptance of the "indefinite value of an image or a sign", similarly to what happens to "iconographic and compositional treatment of themes in figurative art".

The latter poses the question of form invention, and its adequacy to "immediate demands in reference to which the type has lost any real value". So we assume that "the typological and the inventive aspect of the creative process are continuous and interlaced - the inventive aspect being merely that of dealing with the demands of the actual historical situation by criticizing and overcoming past solutions deposited and synthesized schematically in the "type"".

Since the 60s type has been used as a design tool by many architects. Even if this analysis transcends the purposes of this paper, it is worth reminding that for Aldo Rossi type is "the very idea of architecture, that which is closest to its essence", whereas typology is 'the analytical moment of architecture', through which a formal constant in a "study of types of elements that cannot be further reduced" can be recognized. ${ }^{2}$

Rafael Moneo also "argued for a double function of description and design"3 "Type is a diffuse concept that contains a constructive solution - one that gives rise to a space and is resolved in a given iconography - but it also speaks of a capacity to grasp, protect, and make sense of those contents that are implicit in its use".

The concept of type has received much criticism from different standpoints: idealistic philosophy "would deny that an architectural typology could in any way be valid."4

Much criticism arise in Europe around this concept and its potential use in architectural design since the end of the 70s, and "type and typology are today often discarded as conservative, static norms". As Micha Bandini observed, by the late 1970s "typology had simply become a conventional explanation of received form."

"We must accept that throughout the seventies it has been an improper use of the notion of type which has proved, in good or bad, most productive.

I believe that today a serious debate on the notion of building type and on its value (not ideological but also as a concrete project tool) can only lead to a

2. Aldo Rossi, L'architettura della città (Padua: Marsilio, 1966), 33.

3. Sam Jacoby, "Type versus typology Introduction," The Journal of Architecture 20, no. 6 (2015): 932.

4. Argan, "Sul concetto di tipologia architettonica," 1962, 96.

5. Micha Bandini, “Typology as a Form of Convention,” AA Files, no. 6 (1984): 74. 
thorough rediscussion."

In conclusion, there is room for further investigating and for better understanding of the meaning and the current use of the idea of type in contemporary architectural design, especially with reference to those contexts or cultures where specific precedent studies lack.

\section{Research Question and Methodology}

Given the interest in the concept of architectural type since the $19^{\text {th }}$ century and the specific influence on design developed since the 60s, the paper question to what extent contemporary Chinese architects use the concept of type.

To address this question, we first of all recall the meaning of type in architecture and we briefly resume the most relevant attitudes and experiences in using architectural type as the basis of architectural design, especially through the works by Rossi and Moneo.

We then identify the role and relevance of type in vernacular Chinese architectures, with specific reference to courtyard-based types in local cultures and regions. We make specific reference to courtyard based vernacular architectures named Siheyuan and Jiangnan.

Furthermore, we analyse two case studies of courtyard-based buildings recently designed by contemporary Chinese architects in the area of Shanghai.

The paper builds on an extensive literature review on type in architecture, as well as on vernacular and contemporary Chinese architectures. Qualitative research methods have been used through case studies and interviews with designers.

\section{Chinese Vernacular Architectures and Type}

Chinese vernacular architectures have formed numerous distinctive regional characteristics in the long process of evolution due to different local environments and construction conditions along with specific cultural backgrounds.

The Mongolian yurts as a housing type in the northern grasslands coincide with the nomads' characteristics: portable, easy to move and built while expressing environment friendly and respect for the site. Cave or earth- sheltered dwellings are common in certain areas of northern China such as Henan, Shaanxi and Shanxi province where the yellow earth (loessial soil) is quite compacted. Cliffside dwellings and sunken courtyard caves are the general types of cave dwellings can be seen throughout the region. Located in the southwest mountainous areas of Fujian province, the Hakka Tulou (earth building) are both accommodation buildings and defensive construction, usually circular or rectangular in shape. In the southwest ethnic minority areas of China also formed a variety of residential building types, such as Dai's "bamboo house", the Tibetan "blockhouse", and the Miao and Tujia's "Stilted dwelling", etc.

6. Vittorio Gregotti, "The Grounds of Typology," Casabella, no. 509-510 (1985): 4. 
The full flowering of Chinese vernacular architecture is epitomized by the northern courtyard-based dwelling (named Siheyuan) where the principles of axiality, balance, and symmetry are well developed and clearly represented. ${ }^{\text {? }}$

As a provisional conclusion, Knapp argues that even if there is no single style defining Chinese house the spatial and structural aspects are defined to an extent which "it is possible to define archetypes and through them better understand the range of variations." 8

\section{Courtyard-based Archetypes in Chinese Architecture: Siheyuan and Jiangnan Courtyard Houses}

The majority of the population from north to south used courtyard houses forming distinct sub-types in different regions (Figure 1). ${ }^{9}$

In the traditional residence, the courtyard attached to the interior space is practical, served as the expansion of internal functions. The most important attribute of the courtyard is the extensibility of the room, rather than the "boundary" of the house. ${ }^{10}$ Therefore, the space beneath the veranda around the central courtyard as the connection of interior space and courtyard plays an important role in traditional daily life. "The occurrence of the courtyard becoming a 'type-form' in China depends on the complement between the room and the courtyard, as well as people into and out of the building."11

As the representative of Chinese courtyard house, the northern 'Siheyuan' (a residential compound with a set of courtyards enclosed by the surrounding buildings and high walls on four sides) has a broad impact on other sub- types of courtyard houses all across China due to its flexible and extendable structure adapting to various site dimensions. ${ }^{12}$ Wealthy and larger families would extend the basic layout by adding additional buildings, verandas and of course, courtyards (Figure 2).

7. Ronald G. Knapp, The Chinese house: Craft, symbol, and the folk tradition (Hong Kong; Oxford: Oxford University Press, 1990), 11.

8. Knapp and Kai-Yin Lo, House, home, family: Living and being Chinese (Honolulu: University of Hawai'i Press, 2005), 34.

9. Peter G. Rowe and Seng Kuan, Architectural Encounters with Essence and Form in Modern China (Cambridge: The MIT Press, 2002), 25.

10. Ming Ge, “Atelier Deshaus's 'Type-form,,” Times+Architecture, no. 5 (2009): 107.

11. Ibid, 108 .

12. Knapp and A. Chester Ong, Chinese houses: The architectural heritage of a nation, 23. 


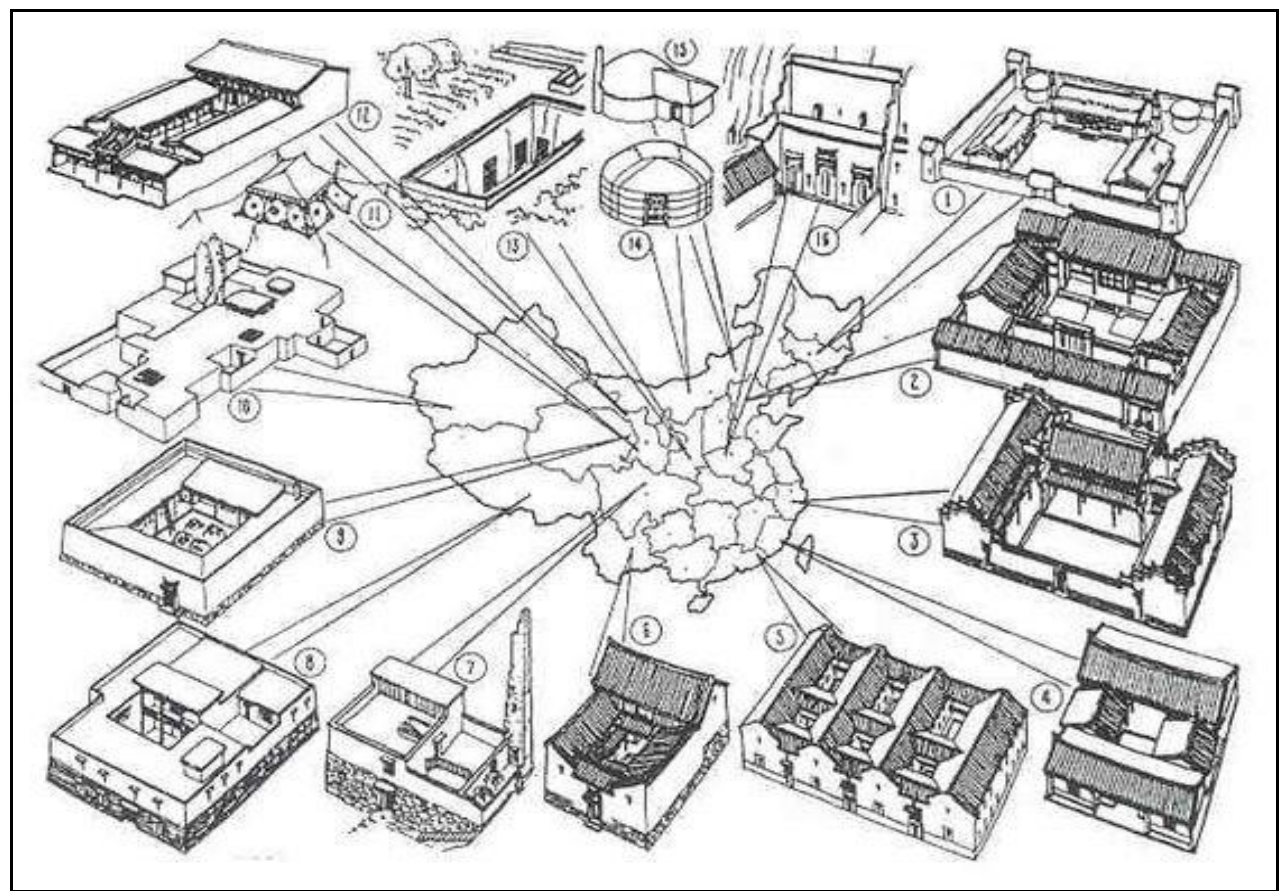

Figure 1. Architectural Types across China Showing the Courtyard as a Common Feature in Vernacular Architectures Source: Zhiping Liu. ${ }^{13}$

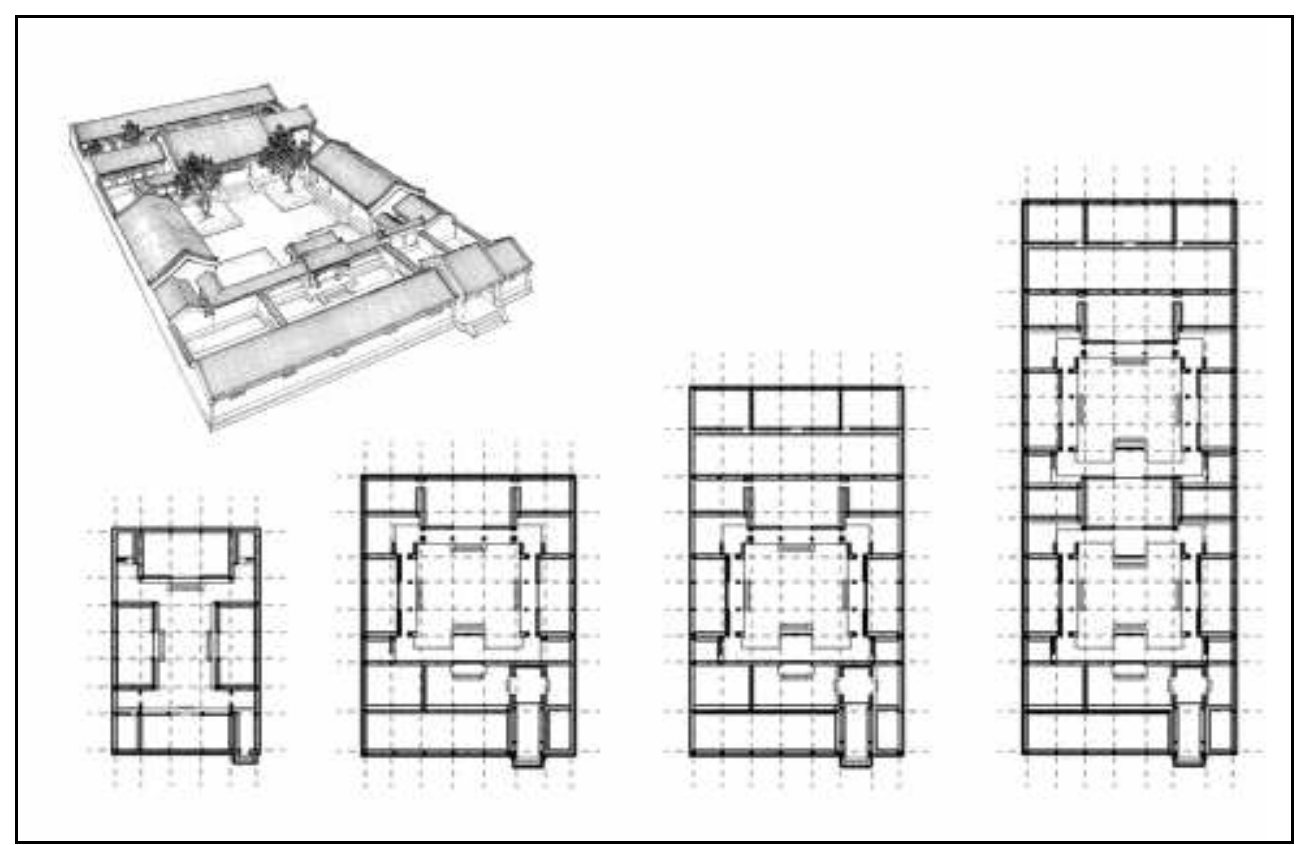

Figure 2. The Basic Layout of Siheyuan and its Transformations Source: Ronald G. Knapp ${ }^{14}$ and Yuwei Wang. ${ }^{15}$

13. Zhiping Liu, A Brief History of Chinese Residential Architecture - Cities, Houses, Gardens (Beijing: China Architecture \& Building Press, 1990), 206.

14. Knapp, China's Vernacular Architecture: House Form and Culture (Honolulu: University of Hawaii Press, 1989).

15. Yuwei Wang, "Persistence of the Collective Urban Model in Beijing," posted by AAPC. 
Meanwhile, this courtyard-house structure is shared by almost all buildings with different functions in China. Ancestral temples, academies, guild halls and even the Empire's Forbidden City can be viewed as types of Siheyuan. Its northsouth orientation, closed structure, clear axiality and balanced side-to-side symmetry reflected the layout principle about the ideal dwelling environment according to the traditional Chinese philosophy of 'feng shui' (known as geomancy in the west.) ${ }^{16}$ The spatial hierarchy brought by the symmetric layout also coincides with the hierarchical relationship between young and old, master and servant in traditional Chinese families. Moreover, Jiangnan courtyard houses which can be seen as a similar version of Siheyuan are distributed in the mid-lower Yangtze River valley and formed their own unique type characteristics in the long period evolution. The northern part of Jiangnan area is crisscrossed with countless canals and lakes while the southern region is distributed with a large number of mountains and hills. ${ }^{17}$ When developing their systems of architecture, the local people were acutely conscious of the construction conditions and tried to come to an understanding with them.

The intimate relationship with the canals can be seen as the first distinct feature of vernacular houses in Jiangnan. Narrow interconnecting streams and canals flow through many villages and towns on the northern lowlands such as Tongli and Zhouzhuang. We can find a large number of houses along the watercourses either directly adjacent to the water or situated upon a raised embankment. ${ }^{18}$ Platforms, overhanging eaves and steps to the river as the common architectural elements can be seen on the water side of the residential compounds for neighborhood interactions and daily washing. Meanwhile, different from Siheyuan which contains brighter colors and paintings in the inner façade, Jiangnan courtyard houses have a unique sense of simplicity: white plaster walls, brown beams, columns, door and window sashes, and black tiles. ${ }^{19}$ People usually use the scene of "small bridges, flowing water and residences" to express the collective memory of traditional Jiangnan courtyard houses.

[August 13, 2012.] https://bit.ly/2H6H0tS.

16. Linda F. Sullivan, "Traditional Chinese Regional Architecture: Chinese Houses," Journal of the Royal Asiatic Society Hong Kong Branch 12 (1972): 133.

17. Knapp, China's Vernacular Architecture: House Form and Culture, 57.

18. Ibid.

19. Donia Zhang, Courtyard Housing and Cultural Sustainability: Theory, Practice, and Product (Abingdon: Routledge, 2013), 79. 


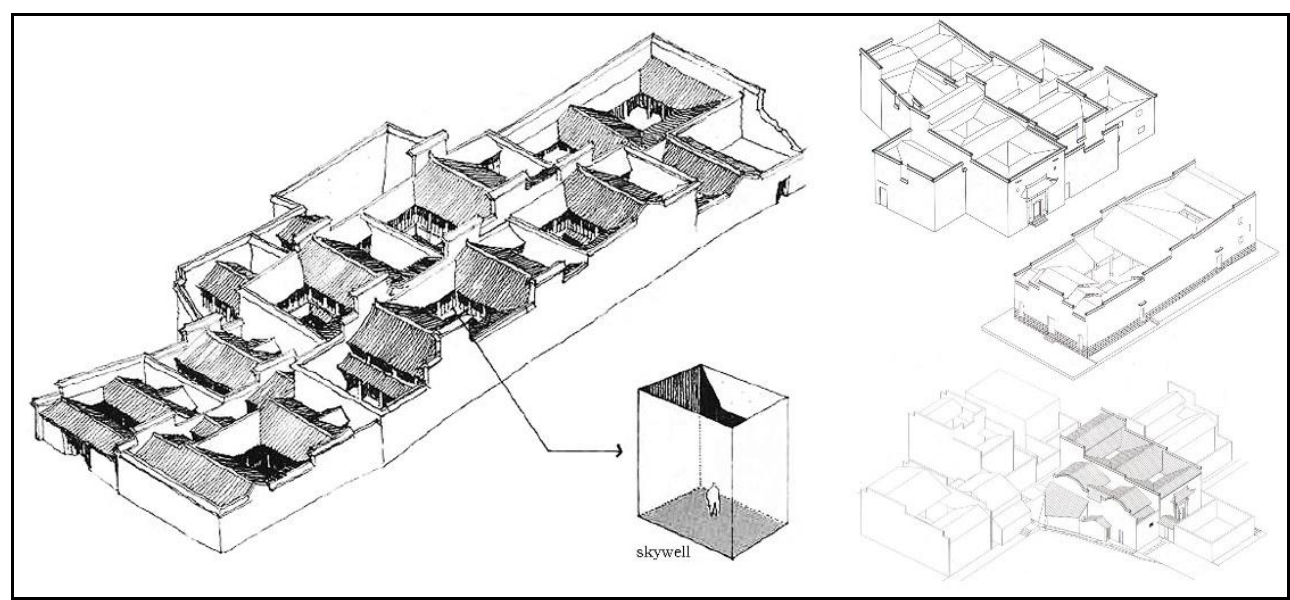

Figure 3. Different Dimensions of Jiangnan Courtyard Based Houses Source: Yigang Peng ${ }^{20}$ and Ming Tong. ${ }^{21}$

The whole layout of the residential compounds does not follow the strict symmetry: it is more compact and flexible than the northern Siheyuan, so that to meet higher population density and less arable land's occupying requirements, consisted of a set of one to two story buildings and internal skywells for ventilation and lighting. These narrow skywells also reduced the direct sunlight, creating a comfortable microclimate for the courtyard life in the hot summer (Figure 3).

Besides the courtyards, gardens are the most welcoming compositions in literati or scholar's houses in the Jiangnan regions, reflecting the elegance, simplicity and poetic meaning in their daily life. Superficially, the garden looks like a bigger courtyard, but the dimension is not the essential difference between them. In the garden, the designer strived to attain the different moods of scenes identified as "where one can walk, view, travel and live",22 by artificially planting trees, piling rockery, drawing water and chiseling pools, or combining the above approaches for landscaping.

20. Yigang Peng, Analysis of the Traditional Chinese Garden (Beijing: China Architecture \& Building Press, 1996), 60.

21. Ming Tong, From Myth to Fairy Tale (Beijing: China Electric Power Press, 2010), 131.

22. Weiquan Zhou, History of Traditional Chinese Garden (Beijing: Tsinghua University Press, 1999), 18. 


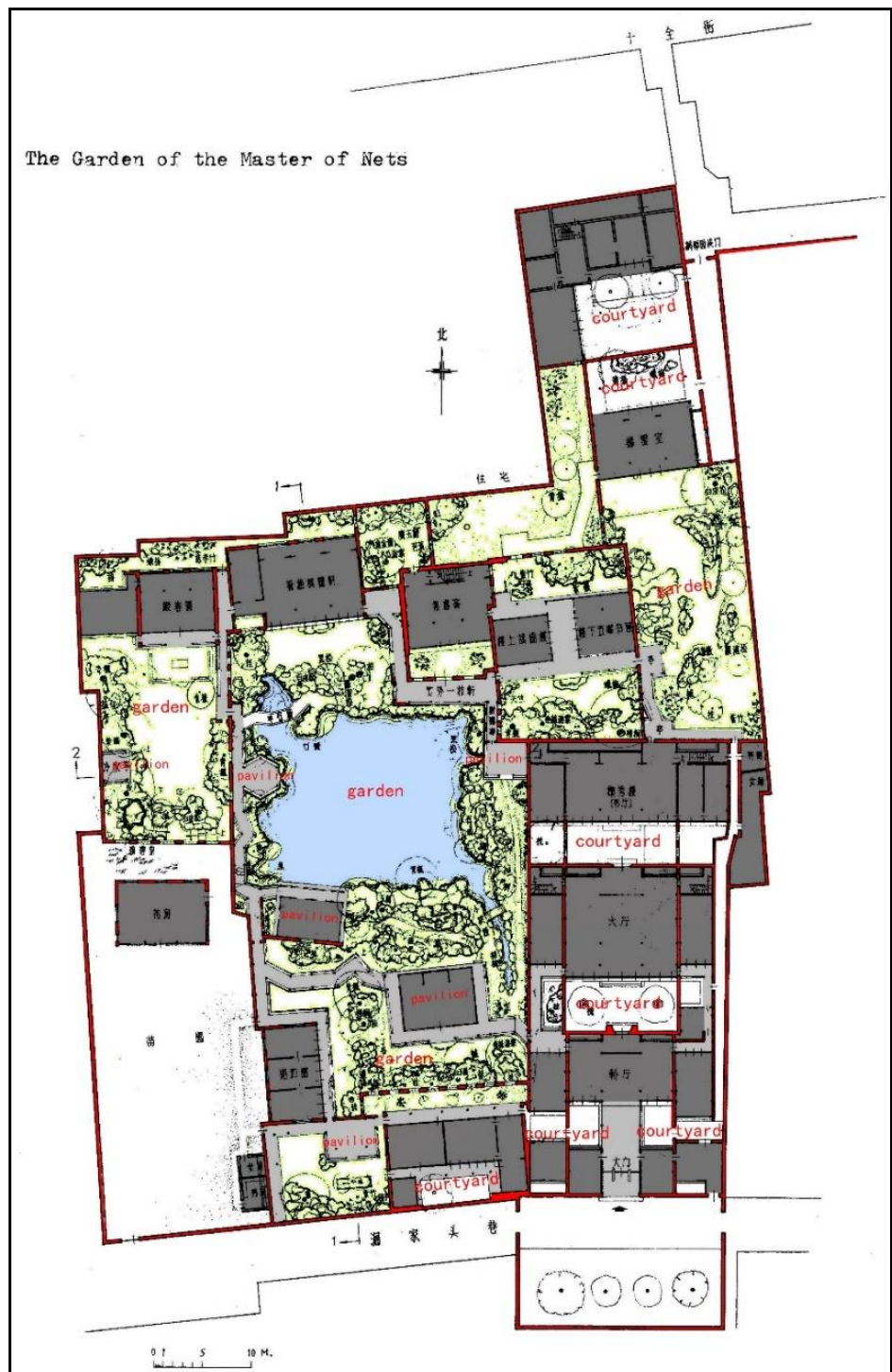

Figure 4. Residence with Associated Gardens Form the Unique 'Garden-House' Pattern in Jiangnan Area

Source: Liu Dunzhen. ${ }^{23}$ Modified by Authors.

By contrast, courtyards may also be adorned with rocks and plants, but only to improve the microenvironment and do not form an independent landscape system. ${ }^{24}$ Housing with associated gardens epitomize the finest forms of domestic architecture in Jiangnan, ${ }^{25}$ forming the unique 'garden-house' pattern which in turn influenced the layout of the northern Siheyuan (Figure 4).

23. Dunzhen Liu, Classical Gardens of Suzhou (Beijing: China Architecture \& Building Press, 1979), 401.

24. Peng, Analysis of the Traditional Chinese Garden, 14.

25. Knapp, China's Vernacular Architecture: House Form and Culture. Honolulu: University of Hawaii Press, 61. 


\section{Contemporary Chinese Architecture}

The paper draws on a literature review on Chinese contemporary architecture and identifies architectural type as one of the design pathways for contemporary Chinese architects. ${ }^{26}$

Even if in the past Zhi Wenjun ${ }^{27}$ observed that "[since the '80s] ... maybe Chinese contemporary architects sometimes copied Western styles or misinterpreted Western concepts, without a careful consideration of the local contexts", nowadays the situation is radically different. Paraphrasing Zheng Shiling's point of view, ${ }^{28}$ they combine international perspectives and activities with local research and teaching, they look for an unconventional way through tradition and modernity, based on society's needs.

Probably some of these features can be currently shared among many Chinese architects, in different regions. Especially the generation of young Chinese architects has had the opportunity to study abroad. Thus, it is a generation that has not just physically returned to China, but more importantly has been looking at how to transfer what they have learned back to the local context. Having had the chance to engage with multi-cultural environments, young Chinese architects transfer design skills and methods, ${ }^{29}$ and not only architectural styles.

The arising of Chinese architects on the international scene (given for example the Pritzker prize by Wang Shu) shows very clearly that young Chinese architects work within the global arena, both by engaging with international events (e.g. the Venice Biennale) or by making reference to other architects and languages, nationally as well as internationally. A review of trans-cultural practices is well beyond the scope of this paper, but represents a field worth of further investigations.

However, it is interesting to note how there is an increasing attitude to link architecture to history and traditions, that is usually expressed in terms of spatial concepts (e.g. the house, man and its environment) or vernacular architectures (e.g. language expression, type, materials), ${ }^{30}$ underpinning the idea of architecture as a form of memory. ${ }^{31}$

26. Ioanni Delsante, Experimental Architecture in Shanghai (Roma: Officina Editore, 2011), 52.

27. Wenjun Zhi, "China under Sea Change, Chinese Contemporary Architecture and globalization," in M8 in China - Contemporary Chinese Architects (ed.) Zhi and Schmal (Berlin: Jovis Verlag, 2009), 8.

28. Shiling Zheng, "The young generation Chinese architects, their maturity and mission," in Experimental Architecture in Shanghai (2011), 12.

29. Angelo Bugatti, "Preface," in Experimental Architecture in Shanghai (2011), 7.

30. Zhenyu Li, Qi Chang and Yijia Dong, "From Housing Efficiency to Urban Efficiency: The Typological Characteristics and Transformation Trends of Contemporary Chinese Residential Buildings," Times+Architecture (2016):7. 16.

31. Shu Wang and Amateur Architecture. Imagining the house (Zurich: Lars Muller, 2012), 


\section{Liantang Town Hall Project in Qinpu}

As previously stated some designers work with explicit reference to architectural type, adhering to typologies that have endured a strong position in the history and culture of the place, as for example the Liantang Town Hall by Atelier Z+.

Located in the southwest of Qingpu District, Shanghai, Liantang is a very typical Jiangnan canal town where the long history of the watery-oriented culture has not simply become a scene for tourism consumption in the inevitable process of modernization. The site of Liantang Town Hall is close to the center area of the new town in plan, surrounded by farmland and without clear physical restraints.

Different from the local government's initial request, a 6-storey building and a large square to reflect 'modernity', the architects chose to continue the town's self-renewal pattern and explore the internalization of the local architectural features in the new construction.

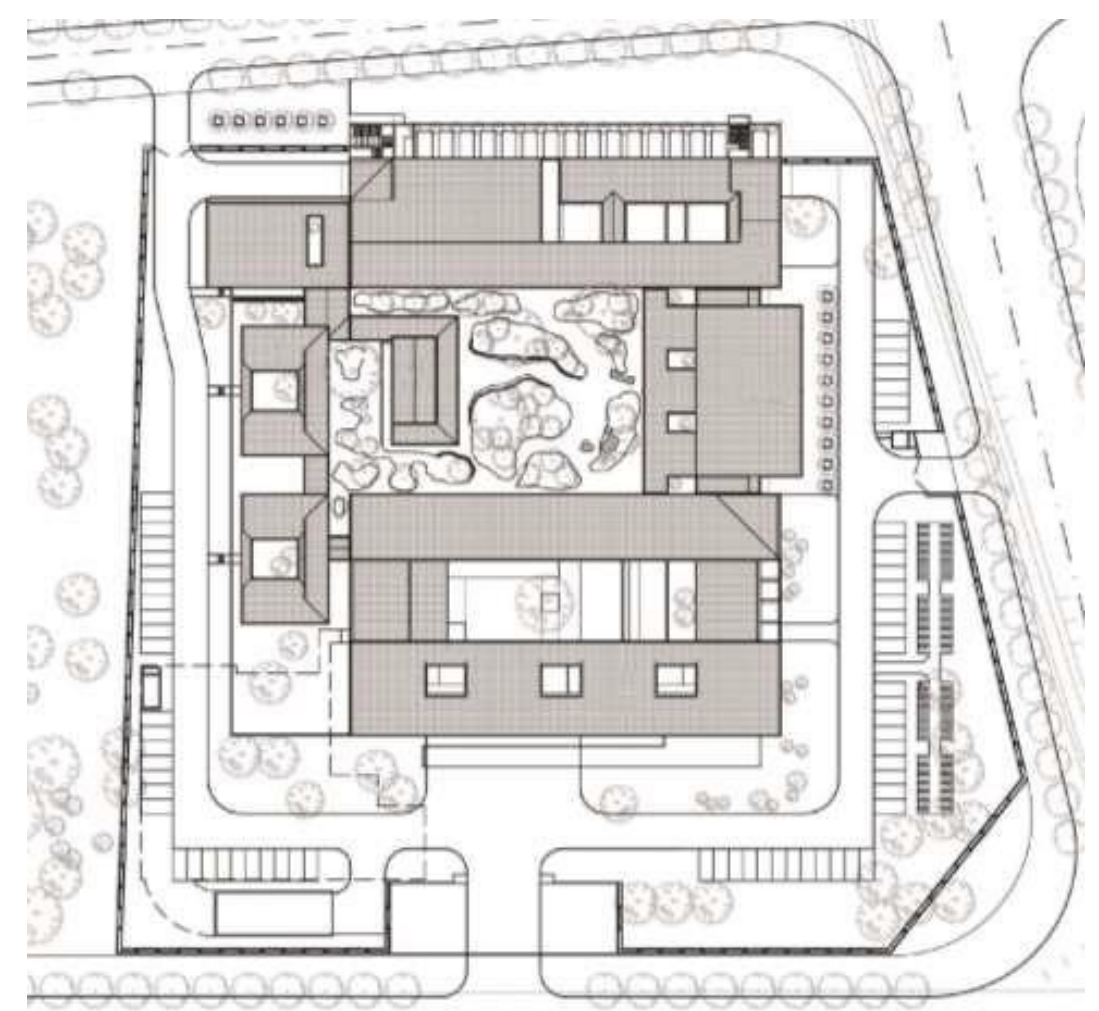

Figure 5. Liangtang Town Hall, Masterplan

Source: Ioanni Delsante. ${ }^{32}$

"We hope to understand the inherited characteristics of the traditional 'Jiangnan' civilization in a conscious manner in relationship between our construction behavior and the living world." 33 The plan is based on an articulated

32. Delsante, Experimental Architecture in Shanghai, 131.

33. Bin Zhang and Wei Zhou, "Interview with Zhang Bing \& Zhou Wei," in Experimental Architecture in Shanghai (2011), 137. 
composition of blocks with patios and courtyards around a central main courtyard, so that "these independent courtyards form different spatial features in a harmonious way, which create a pleasant working environment". The entire complex is characterized by a boundary wall that (in spite of openings and welldefined points of entry) defines the building limit and contributes to a unified composition, allowing the basic executive building to extend horizontally to make better use of the site conditions, breaking through the stereotyped image of 'administrative center' (Figure 5).

An open and amiable public appearance as a functional requirement break through the scale restriction of the traditional courtyard space, so at least two phases of space planning can be distinguished: one is of a congregational character and corresponds to the central space as in the courtyard within the main building that the user enters. The other instead is with regard to the patios of the secondary blocks that correspond to ancillary functions and define spaces that are more enclosed and private.

These independent courtyards generate a consequence of spatial relations: a three-storied office building with a big courtyard in the center is located in front of the south entry square while the east part is the community service center opened to the public. The north part of the project is designed as the conference center and logistics services with a double-storied veranda facing the main courtyard. The main executive functional offices constituting three small courtyards are located in the west part". Meanwhile, the main courtyard can be interpreted as a traditional Chinese garden with a "pavilion" used for a library in it, separating the garden into two distinct parts.

The references to type are accompanied by a refined composition of the sloped roofs that help to delineate enclosed and open spaces: "The building presents an image of continuous courtyards with white walls and single slope roofs with black tiles as its main characteristics. The delicate details require appropriate materials and tectonics with local style, as well as feasible creativity".

\section{Ten Courtyard Houses Project in Suzhou}

The Ten courtyard houses project by Tong Ming is for individual houses and works by demonstrating with great clarity how to react against uniformity and trivialization of typologies and planning employed in recent residential quarters that are independent of the urban influences.

The new socio-economic path in contemporary China is recognizable in the rise of numerous real estate initiatives that are part of the urban development program based on new developments. These initiatives include individual interventions, unconnected with the surrounding urban fabric, often based on the logic of cluster planning or in any case result in fenced quarters, closed to the outside, that follow residential models imported from abroad and based on the obsessive repetition of single family homes with a small private garden attached to it. $^{34}$ As part of Tianya Villa Community located in the northern suburbs of

34. Li, Chang and Dong, "From Housing Efficiency to Urban Efficiency: The Typological 
Suzhou, the Ten Courtyard houses project has been delivered by a team of six architects with Tong Ming as chief architect.

At the beginning, the idea of courtyard house was among all the architects, addressing the question of how to realize the quality of traditional courtyard houses in modern villas, and how to improve with modern construction technologies the living conditions of traditional housing. ${ }^{35}$

"In the search for the idea, the original design of single free standing villas was de-architecturalised, dismantled and reconfigured in a new program, minimizing the merit from the rational structure, the formalistic appearance, the specific spaces and the elegant details." 36
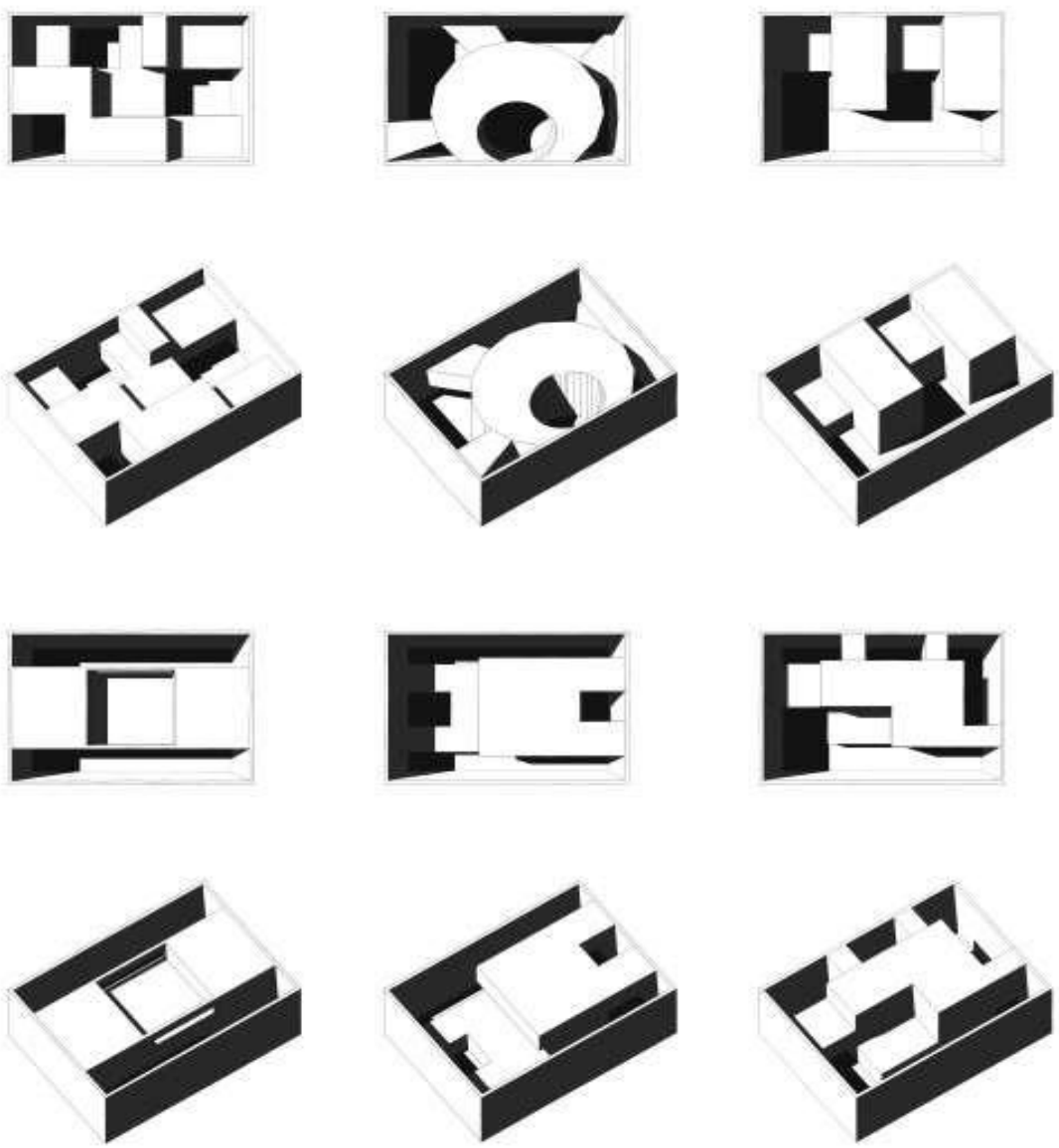

Figure 6. Ten Courtyard 3D Conceptual Models

Source: Ming Tong. ${ }^{37}$

Characteristics and Transformation Trends of Contemporary Chinese Residential Buildings," 16.

35. Tong, From Myth to Fairy Tale, chap 1.

36. Tong, "Ten Courtyard Houses," Times+ Architecture, no. 1 (2006): 39.

37. Tong, From Myth to Fairy Tale, 76. 
With reference to the specific spatial operation, the enclosed boundary wall was firstly used to define a kind of inside and outside system. Subsequently, the inner house combined with the wall established a secondary relationship about interior and exterior, that is the well-organized functional rooms and the courtyards. The interweaving of these two kinds of internal and external system leads to the richness, complexity as well as fragmentation of the courtyard space in each items of the Ten Courtyard houses, achieving the complete fusion of inside space and outside space in order to practically extend using area to the courtyard (Figure 6). At the same time, it brings about flexibility of creating space depending on various outside elements such as water, rockery, etc., which somehow allows users to contribute themselves in arranging their own space. ${ }^{38}$ Finally "each result reveals the new possibility. This strategy enables the relationship of housing to be imagined differently, an architecture free from delusive notions", and thus maximize approaching the reality of a city: uniform typology and various individualities.

\section{Conclusions}

The selected case studies show the relevance of architectural type in the creative and design processes by contemporary Chinese architects. However, the attitudes of the designers are indeed different, reflecting the richness and complexity of the actual debate on type developed since the $60 \mathrm{~s}$.

Looking at Atelier $\mathrm{Z}+$ and the design of Liangtang Town Hall, we find reference to type as sublimation of an idea, as well as its adaptation to contemporary needs. As the authors state 39 "we explored inheriting and refreshing internal structures of traditional 'Jiangnan' architecture, and internationalization of local architectural features". But at the same time they are interested in typology as it "enables us to see in a historical view the meticulous connected relationship between sites, architecture and people". For Atelier Z+ the real essence of architecture lies in the complex relationship with site and users' lifestyle, rather than in the pure form of buildings. So type is not seen as an "abstract thinking" nor a "direct form generation tool" but rather the way to link architecture, people and place. In this respect, historical typological references can actively contribute to recreate spaces for current needs and aspirations.

The Ten Courtyard houses case study, instead, shows the reference to type as the very essence of architecture. ${ }^{40}$ Even if the project criticizes the urbanization process and its repetitive banalization of housing types, Tong $\mathrm{Ming}^{41}$ states the point is not the repetition itself, that belongs to traditional types in cities as well. Given the project team (composed by 6 architects) and the need for repetition (in

38. Ibid.

39. Bin Zhang and Wei Zhou, "The Internalization of 'Jiangnan'," Architectural Journal, no. 4 (2011): 98.

40. Rossi, "Introduzione," in Architettura Razionale, XV Triennale di Milano. Sezione Internazionale di Architettura (Milan: Franco Angeli Editore, 1973), 17.

41. Tong, "Interview with Tong Ming," in Experimental Architecture in Shanghai (2011), 117-119. 
and beyond the project site), the architects identified type as the element in which simultaneously stand history and contemporary needs, typology and flexible layouts. Outcome of a research by design process, the architects "tried to figure out some kind of combinatory forms as an operational strategy to create new villas. We approach the project with dual interests, one dealing with the inner lives of the houses, $[\ldots]$ the other with urban typology". By reflecting on architectural type, Chinese architects oppose cultural resistance to trivialization of the architectural types, and recognize specific aspects of living.

By using type as a conceptual scheme to be adapted to users' needs or to specific urban settings, contemporary Chinese architects demonstrate the relevance of the matter. Further investigations are needed, and these could be based for example on the selection of a larger number of case studies or by focusing on various types of buildings.

\section{Bibliography}

Argan, Giulio C. "Sul concetto di tipologia architettonica" [On the Typology of Architecture.] In Festsschrift für Hans Sedlmayr. Edited by Karl Oettinger and Mohammed Rassem, Munich: Beck, 1962, 96-101.

Bandini, Micha. "Typology as a Form of Convention." AA Files, no. 6 (1984): 73-82.

Bugatti, Angelo. "Preface." In Experimental Architecture in Shanghai (2011): 7-10.

Delsante, Ioanni. Experimental Architecture in Shanghai. Roma: Officina Editore, 2011.

Ge, Ming. “Atelier Deshaus's 'Type-form'.” Times+Architecture, no. 5 (2009): 106-111.

Gregotti, Vittorio. "The Grounds of Typology." Casabella, no. 509-510 (1985): 4-7.

Jacoby, Sam. "Type versus typology Introduction." The Journal of Architecture 20, no. 6 (2015): 931-937.

Knapp, Ronald G. China's Vernacular Architecture: House Form and Culture. Honolulu: University of Hawaii Press, 1989.

. The Chinese house: Craft, symbol, and the folk tradition. Hong Kong; Oxford: Oxford University Press, 1990.

Knapp, Ronald G., and A. Chester Ong. Chinese houses: The architectural heritage of a nation. North Clarendon, Vt: Tuttle, 2005.

Knapp, Ronald G., and Kai-Yin Lo. House, home, family: Living and being Chinese. Honolulu: University of Hawai'i Press, 2005.

Li, Zhenyu, Qi Chang, and Yijia Dong. "From Housing Efficiency to Urban Efficiency: The Typological Characteristics and Transformation Trends of Contemporary Chinese Residential Buildings.” Times+Architecture (2016): 6-14.

Liu, Dunzhen. Classical Gardens of Suzhou. Beijing: China Architecture \& Building Press, 1979.

Liu, Zhiping. A Brief History of Chinese Residential Architecture - Cities, Houses, Gardens. Beijing: China Architecture \& Building Press, 1990.

Peng, Yigang. Analysis of the Traditional Chinese Garden. Beijing: China Architecture \& Building Press, 1996.

Rossi, Aldo. "Introduzione." [Introduction.] In Architettura Razionale, XV Triennale di Milano. Sezione Internazionale di Architettura. Milan: Franco Angeli Editore, 1973, 17-18. . L'architettura della città [The Architecture of the City.] Padua: Marsilio. 1966.

Rowe, Peter G., and Kuan, Seng. Architectural Encounters with Essence and Form in 
Modern China. Cambridge: The MIT Press, 2002.

Sullivan, Linda F. "Traditional Chinese Regional Architecture: Chinese Houses." Journal of the Royal Asiatic Society Hong Kong Branch 12 (1972).

Tong, Ming. "Ten Courtyard Houses.” Times+ Architecture, no. 1 (2006): 39. . From Myth to Fairy Tale. Beijing: China Electric Power Press, 2010. . "Interview with Tong Ming". In Experimental Architecture in Shanghai, 2011, 117119.

Wang, Shu, and Amateur Architecture. Imagining the house. Zurich: Lars Muller, 2012.

Wang, Yuwei. "Persistence of the Collective Urban Model in Beijing." Posted by AAPC. [August 13, 2012]. https://bit.ly/2H6H0tS.

Zhang, Bin, and Zhou, Wei. "Interview with Zhang Bing \& Zhou Wei." In Experimental Architecture in Shanghai. 2011, 137-139.

. "The Internalization of 'Jiangnan'.” Architectural Journal, no. 4 (2011): 98-99.

$\bar{Z}$ Zhang, Donia. Courtyard Housing and Cultural Sustainability: Theory, Practice, and Product. Abingdon: Routledge, 2013.

Zheng, Shiling. "The young generation Chinese architects, their maturity and mission." In Experimental Architecture in Shanghai. 2011, 11-13.

Zhi, Wenjun. "China under Sea Change, Chinese Contemporary Architecture and globalization." In M8 in China - Contemporary Chinese Architects. Edited by Zhi and Schmal. Berlin: Jovis Verlag, 2009, 7-8.

Zhou, Weiquan. History of Traditional Chinese Garden. Beijing: Tsinghua University Press, 1999. 
